If development ethics

seeks to give accounts

of development that are

philosophically, ethically,

and culturally embedded,

then it strikes me as a

worthwhile project to allow

for a contribution from

an oft-neglected African

perspective. 


\section{Ubuntu and Development: An African Conception of Development Motsamai Molefe}

This article articulates an African conception of development. I call such an account African insofar as it is based on the moral worldview of ubuntu, which is salient largely among the Bantu peoples. To articulate a conception of development, I rely on the paradigm of development ethics, which construes development as an ethical or philosophical enterprise constituted by three questions: what is a good life? what is a just society? and what duties do we owe to the environment? Answers to these questions constitute a conception of development. This article answers two of these questions in the light of ubuntu. Ultimately, I argue that a good life is a function of having a virtuous character, and a just society is one that respects persons in their capacity for virtue and operates on the moral logic of the common good. I conclude by considering the means prized by ubuntu for pursuing the goal of development-the ethics of means.

\section{Introduction}

The concept of development is an essentially contested one /Collier et al. 2006), ${ }_{1}$ admitting to a variety of incommensurably competing interpretations. Historically, much of the discourse on development has been construed within the dominating discipline of economics. For example, Ben Fine (2009) offers a rough history of development studies. In its inception as a field, it was largely dominated by (mono)-economics, namely the Washington consensus and the post-Washington consensus. More recently, however, people talk of development with a human face, characterized by attempts to rethink development as a social science problem, wherein many disciplines can contribute to its conceptualization (Fine 2009, 896).

Talk of development with a human face is reminiscent of an approach to the study of development called development ethics, which understands development primarily as a philosophical and ethical enterprise (Crocker 1991; Dower 2008; Goulet 1996). At the heart of development ethics is a 
conception of development underpinned by three philosophical questions (Goulet 1995): the first question pertains to the nature of a good life, the second grapples with the nature of a just society, and the last involves our relationship and duties to the environment. Development ethics rethinks the concept of development in the light of these questions.

The concept of development privileges moral issues over economical ones (Goulet 1996, 1160; Sen 1987, 2-3). The point is not so much to dismiss economics in the discourse of development, but to understand its role as a means and it (development) itself as a moral end (Sen 1987). Ultimately, in the light of development ethics, development is understood as a process of change from one state to another, pursuing a particular moral ideal, like well-being (Dower 2008, 184). The desired state is characterized as an improvement, a desirable, or a good; these are value-laden terms. In other words, development as a goal is captured by some ultimate moral end(s), be it well-being, dignity, or eudaimonia. In fact, Goulet, a pioneer of development ethics, states:

\begin{abstract}
Ethical judgements regarding the good life, the just society, and the quality of relations among people and with nature always serve, explicitly or implicitly, as operational criteria for development planners and researchers. Development ethics is that new discipline which deals ex professo with such normative issues. $(1995,2)$
\end{abstract}

Thus, we come to terms with the view that development involves moral goals valued in relation to the individual (dignity, well-being), society (just, equal), and the environment. Development ethics is concerned not just with questions of (moral) ends, but with questions of means-the ethics of means (Dower 2008). There are different and competing ways to go about pursuing the ideals associated with development. The task of development ethics is to select the paths that are morally justified. Development ethics therefore imagines development entirely as a moral concept, insofar as both the means qua options or routes for pursuing it and the moral ends (like well-being) that constitute it are intrinsically moral considerations.

To the best of my knowledge, I am unaware of any attempt in the literature to construe an African conception of development as ubuntu in the light of the paradigm of development ethics. If development ethics seeks to give accounts of development that are philosophically, ethically, and culturally embedded, then it strikes me as a worthwhile project to allow for a contribution from an oft-neglected African perspective. My preoccupation here largely focuses on giving an account of a just society; that is, I set myself the goal of answering two of the three ancient philosophical questions posed by development ethics, drawing from moral insights of ubuntu: what is a good life? and what is a just society? ? $^{2}$ Theoretically responding to these questions is tantamount to offering an African conception of what is to count as a good human life and specifying social arrangements required for such a 
life to be possible-which is, in part, an African conception of development. Furthermore, to be complete, this conception of development must furnish us with details regarding the means it will prescribe for pursuing development (the ethics of means), i.e., the principle it will prescribe for selecting among competing options and routes to pursue the goal of development. This article is one way to add voices from the Global South on the issues of development alongside the new theoretical contributions of Capability Approaches by Amartya Sen and Martha Nussbaum, among others.

Ubuntu has been construed as a moral theory (Metz 2011; Ramose 1999; Shutte 2001). It has been applied to a variety of social problems. For example, it has been invoked to reimagine the political project of South Africa (Molefe and Magam, 2019; Shutte 2001), to foster reconciliation in the post-apartheid society (Tutu 1999), to imagine a bill of rights in the South African constitution (Metz 2011; Mokgoro 1998), to stand as a basis for public policy (Nkondo 2007), and to imagine management theory (Lutz 2009; Mbigi 2005). Little research, however, has gone into considering how ubuntu could ground a theoretical conception of development, let alone in the framework of development ethics. It is to this task that I dedicate this article.

I do not aim here to argue that this is the only way to think about development in the African tradition, or even to suggest that this is the most plausible way to do so. At the very least, this article sets itself the limited goal of giving the reader the moral picture of development in the light of ubuntu as a moral theory, which it understands as a particular arrangement of society in ways favorable for human flourishing. Before arguing for the plausibility of this conception, a task that is beyond the scope of this article, it is important to get a sense of this African conception of development.

I structure this analysis as follows. I begin this article by familiarizing the reader with ubuntu as a moral theory. Ubuntu has many interpretations as a moral theory; here, I shall select the salient interpretation of it in the literature: the self-realization approach to ethics (Molefe 2019; Van Niekerk $2007,364)$. Second, I respond to the two questions posed by development ethics: what is a good life according to ubuntu? And what is a just society according to ubuntu? In the final section, I consider what ubuntu offers in terms of the ethics of means.

\section{Ubuntu as a Moral Theory}

There are competing conceptions of ubuntu as a moral theory. Two such conceptions strike me as salient, the relationship and self-realization approaches. ${ }^{3}$ The latter, advocated by Desmond Tutu and philosophically defended by Thaddeus Metz, at least according to my estimation, has come to dominate the literature on African ethics (Metz 2007a, 2009). On this reading of ubuntu, the highest good is some relationship, specifically, communal or harmonious ones (Metz 2007b, 2016; Tutu 1999). Right actions are 
those that are characteristically harmonious, or a virtuous human being is one whose deportment connects with others in a morally relevant way (Metz 2007, 2010; Tutu 1999). Metz construes harmony in terms of friendship, friendliness, or love $(2007,336,2009,52)$. Morality, in this understanding of ubuntu, is entirely a function of relating with others positively (Metz 2010, 84). According to Metz, these relationships constitute the whole gamut of morality. Elsewhere, I have argued that a relationship-based account of ubuntu is implausible (Molefe 2017a, 2017b).

In what follows, I focus on (though I do not defend its plausibility) what I take to be a more promising understanding of ubuntu-the self-realization approach, best illuminated by analyzing the maxim that captures Ubuntu: "a person is a person through other persons." This maxim can be divided into three facets that constitute the moral truth embedded in this worldview: ontological personhood, normative personhood, and the means required to achieve normative personhood. The first instance of the word person, in the maxim, is an ontological one referring to a thing called a human being and the moral potential it possesses. Human nature is believed to be naturally endowed with the quality or moral capacities that can be morally developed (Munyaka and Mothlabi 2009, 68). It is for this reason that Sebidi $(1988,84$; emphasis mine) notes:

\begin{abstract}
For Africans human nature is capable of increasing or decreasing almost to a point of total extinction. There are actions ... that are conducive to the enhancement or growth of a person's nature, just as there are those which are destructive of a person's nature.
\end{abstract}

In this moral scheme, there is no talk of a so-called original sin, which understands human nature to be naturally or morally depraved. Human nature, in African ethical thought, is believed to be loaded with moral possibilities-note, not guarantees (Biko 2004; Gyekye 1992). The fulfilment or achievement of its moral possibilities is captured by the second reference to personhood in the maxim, which is typically captured in the literature as the normative notion of personhood (Ikuenobe 2006; Wiredu 1996). ${ }^{4}$ To be called a person, in the second sense, it is to be morally praised for converting what was merely a moral potential into a moral reality, usually understood in terms of a sound character (Menkiti 1984; Wiredu 2009). The conversion of the moral possibilities to moral personhood captures the reason why this moral theory is construed in terms of moral perfection or self-realization. The agent is expected to convert the raw moral potential of her human nature to be an embodiment of a sound character or moral excellence.

Scholars of African moral thought speak of the progression from the natural to the moral in this fashion. Augustine Shutte $(2001,30)$, in his book on ubuntu, notes: 
[T] he moral life is seen as a process of personal growth. . . Our deepest moral obligation is to become more fully human. And this means entering more and more deeply into community with others. So although the goal is personal fulfilment, selfishness is excluded.

Shutte construes ubuntu in terms of personal moral growth, where the agent progresses to become more fully human, to have ubuntu. Metz $(2010,83$, emphasis original), a leading scholar of ubuntu, notes:

The ultimate goal of a person, self, or human in the biological sense should be to become a full person, a real self, or a genuine human being, i.e., to exhibit virtue in a way that not everyone ends up doing.

It is clear that Metz conceives of morality as a journey from the merely biological to the moral. In other words, the goal of morality is to achieve the status of being a full, real, or even genuine self. He construes full, real, and genuine humanity to amount to developing a morally virtuous character.

Certain other leading scholars of African moral thought do not use the term ubuntu, but use the normative idea of personhood, which is central to discourse about it. I assume that even though these scholars do not use the idea of ubuntu, when they talk of personhood, they are referring to the same moral system that requires the perfection of our character. For example, Ifeanyi Menkiti talks of personhood in terms of a progression from the natural, merely being human, to being a person, one characterized by a "widened maturity of ethical sense," or one "with all inbuilt excellencies implied by the term" (1984, 176, 172).

Scholars thus tend to reduce ubuntu to a character-based ethical theory (Behrens 2013; Gyekye 2010). How African scholars specifically think of the agent characterized by ubuntu is a crucial point: they tend to think of ubuntu, or one that has it, in terms of relational moral properties or virtues. Tutu $(1999,35)$ notes:

When we want to give high praise to someone we say, "Yu, u nobuntu"; "Hey, so-and-so has ubuntu." Then you are generous, you are hospitable, you are friendly and caring and compassionate. You share what you have. It is to say, "My humanity is caught up, is inextricably bound up in yours."

Though Tutu does not define in precise terms what it means to have ubuntu, he does give us a rough sense of what is involved in it. In the first instance, when we say someone has ubuntu, we are praising her highly; we are praising the moral agent for her moral efforts and achievements. How do we recognize these moral achievements? These are best recognized in terms of relational moral virtues, like being generous, loving, caring, and so on. In other words, 
though ubuntu is a quality of the character of an individual, it is best exemplified in terms of other-regarding duties, or even virtues of compassion, generosity, kindness, friendliness. One that has ubuntu is one whose deportment and disposition is oriented toward "community-building" (Molefe, 2019, ch. 2; Munyaka and Mothlabi 2009, 65).

The moral emphasis of ubuntu as an ethical discourse is other-regarding. For example, Gyekye (2010) notes that "African ethics is, thus, a characterbased ethics that maintains that the quality of the individual's character is most fundamental in our moral life." Gyekye thinks of the good character in terms of "practice of virtue" $(1992,109)$. He is quite specific about the moral virtues characteristic of personhood when he notes that personhood "includes generosity, kindness, compassion, respect and concern for others ... or behaviour that conduces to the promotion of the welfare of others." The same can be said about Wiredu when he opines: "a person . . . is a morally sound adult who has demonstrated in practice a sense of responsibility to household, lineage and society at large" $\left(2009,15\right.$; see also 1992, 200). ${ }^{5}$

The discussion above shows that the notion of ubuntu/personhood is understood to embody a sound character as the goal of morality, which is typically construed in terms of other-regarding duties or relational moral virtues. This should not come as a surprise, given the communitarian nature of this ethical framework. The idea that ubuntu extols relational virtues tells us something about what is taken to be distinctive about human nature, in the morally relevant sense, according to this moral theory. The most crucial or morally relevant facet of human nature is our social nature, our ability to connect to others. This point is suggested above by Tutu, when he notes that our humanity is inextricably bound to that of other human beings. This comment is instructive of how to understand the crucial facets of human nature: "The African individual is a communal being, inseparable from and incomplete without others" (Munyaka and Mothlabi 2009, 68). This point is captured by emphasizing our common humanity and destiny (Gyekye 1992; Lutz 2009). The most important moral facet of our nature to be developed is thus that which binds us to others-hence, the high prize placed on relational moral virtues.

This talk of the distinctive human capacities that are essential in the discourse of ubuntu leads to the last facet of the maxim of ubuntu: "through other persons" speaks to the issue of means, how to achieve ubuntu/personhood. The reader should note the moral logic of this moral theory: it begins by drawing our attention to human nature, which it understands in terms of its capacity to relate with others; it then proceeds to capture the goal of this theory, the normative notion of personhood, in terms of the agent exuding relational moral virtues. The last part of the theory concerns the question of how to develop human nature to achieve personhood. The answer expressed in the maxim prescribes social relationships as the only and best means to achieve personhood.

The reasoning behind the prescription of social relationships as the best means to achieve a sound character is that we have no better way to 
develop relational virtues than just to be involved in such relationships. This comment is instructive: "A person is incomplete without others. He or she needs others to be fully human" (Munyaka and Mothlabi 2009, 69). It is for this reason that Shutte states that one can achieve full humanity by entering more and more into social relationships. I think Menkiti's (1984, 172) talk of personhood being possible only in the context of incorporation into the community is informed by the same logic. Benezet Bujo's $(1997,28)$ comments about how to achieve moral virtue are spot on:

It is exactly the community which enables the self-realisation of the individual. According to the African representation of values, it is not possible to achieve the ethical ideal individually or as a strictly personal achievement.

Though it is the individual that achieves moral virtue, she cannot do so all by herself. She needs to be embedded in a community that prescribes moral standards, and the agent has to engage and practice morality in constant contact with others. It is for this reason that Menkiti insists that African "morality demands a point of view best described as one of beingness-withothers" $(2004,324)$. The crucial point here is that, in this moral approach, relationships are not optional: they are an inescapable necessity for the possibility of morality. Not every form of relationship counts as morally relevant; it is those that grow our capacity to connect with others positively that do the moral job.

Above, I gave the reader the sense of ubuntu as a moral theory understood in terms of the self-realization approach. Below, I turn to consider development ethics in terms of ubuntu.

\section{Ubuntu and Development Ethics}

Below I consider the two central questions in the discourse of development ethics in the light of ubuntu. The first question pertains to the nature of the good life. In our exposition of ubuntu as a moral theory, we have already furnished an answer to this question. One way to answer it is in terms of asking: what is the moral goal according to ubuntu? The goal of ubuntu is captured by the normative notion of personhood. The good life is a function of the individual's ability to develop her distinctive moral capacities, which in the African tradition is understood to be her social nature (Lutz 2009; Mbigi 2005). A good life therefore, we noted, is a function of the agent living a life exuberant with other-regarding virtues, like being generous, loving, friendly, sharing, having empathy, and so on.

The second question - pertaining to the question of what constitutes a just society-is yet to be answered in the light of ubuntu as a moral theory. This question in some sense is political, insofar as it deals with the question of how to order society with the single overarching theoretical burden of 
what it means to give everyone their due, concerned with what "the shape our social life should have as a whole" (Larmore 2012,2). The idea of politics is therefore understood to be concerned about the public sphere; it involves unfolding the underlying values that are to organize the shape of our social life as a whole, in order to see whether it is fair or gives everyone their due. Politics, understood in this way, is nothing but an extension of ethics; it is just applied ethics (Larmore 2012, 2-3; Wiredu 2009, 15).

To ask the question "what is a just society?" we are trying to delineate the content of the value(s) that ought to shape our social life as a whole. An implication of this understanding of politics is that it construes this question to imply that the political, in some sense, must inform the moral. To give an example that gives intuitive support for why I take the political to be prior to the moral, consider a case of a sexist society. A society whose shape of social life favors men over women constricts women's social and moral possibilities (Molefe 2018a). As a point of departure, it is safe to open our elucidation on the question of a just society by submitting that it is characteristically one that renders the moral possible. A society is just if it allows all individuals to be able to pursue the good life (ubuntu), or if it makes that pursuit possible in terms of social arrangements.

The pursuit of a good life is each individual's responsibility. It requires, however, a robust organization of the whole social life. The crucial question then to pursue is: what are the basic conditions and/or features of a just society that will render the moral (the pursuit of ubuntu/personhood) possible for all?

Thus far, at least, we can rightly suppose that a just society is one that is arranged to create conditions conducive for human beings to achieve personhood; however, I need to be fairly specific about some of these conditions-in other words, to be unequivocal about the basic goods or values that are necessary for human beings to pursue moral perfection (ubuntu). This consideration forces us to ask two related questions. On the one hand, we have to grapple with the conditions that might permit all human beings to stand as equals in society (moral egalitarianism), and on the other hand, we have to reflect on the basic goods that are necessary for human beings to self-realize (the common good).

\section{The Condition of Equality}

The first consideration central to questions of justice pertains to human nature. It seeks to understand the facets of human nature in virtue of possession of which human beings come to stand in the comity of justice. What is the distinctive feature of human nature that accounts for their moral status (dignity) and therefore their equality to every other individual in society? To best illuminate this point, take John Rawls's theory of justice, according to which individuals are objects of justice precisely because they possess the capacity for reason (we owe them respect), and it is this capacity that allows 
them to be equal to every other individual and allows them to be party (as subjects) in the initial situation.

The idea of moral status refers to the feature of human nature by which human beings are owed direct duties of respect (DeGrazia 2008; Toscano 2011). It is in recognition of some ontological feature, the special feature by which all human beings deserve equal moral regard (Darwall 1977). The respect anticipated here tracks ontology, where one is respected merely because they possess the relevant onto-moral properties. In Rawls's account, moral status (which secures the equality of all human beings) is a function of our capacity to reason. According to ubuntu, in contrast, human beings have moral status in light of their capacity to develop morally virtuous characters (Gyekye 1992, 109-13).

According to ubuntu, a just society is one that recognizes the humanity-the distinctive feature that accounts for equality-of others for what it is. It is for this reason therefore that Ramose $(2009,308$; emphasis mine) notes:

Most African languages have in their vernacular a saying synonymous with the Sotho, motho ke motho ka batho. This means that to be human is to affirm one's humanness by recognizing the same quality in others and, on that basis, establishing humane relations with them.

Here, Ramose informs us that ubuntu requires us to recognize the quality (ontological feature) that accounts for the moral status of all human beings. This (ontological) quality is the same among all human beings. Ubuntu, first and foremost, requires us to recognize that it is a feature of all human beings as the basis for the equal respect we owe to them. It requires us to have a correct understanding of human beings and the quality that marks them out as special in the world, or what makes them to count as a privileged part of nature (Ramose 2009, 309). To further make this point, Ramose invokes a moral maxim, feta kgomo o tsware motho, that he construes to amount to the following philosophical rendition:

the practice of feta kgomo o tshware motho ... requires the moral education based upon the principles of sharing, concern for one another and the subordination of wealth to the dignity of the human person as motho. $(2010,302)$

Motho is the Sotho word for a human being, as kgomo is for a cow. In most African traditional cultures, cows represent wealth. The significance of this saying is reminiscent of Kant's distinction between price and worth (Kant 1996). A cow's value is captured in terms of price insofar as it varies according to external circumstances of the market; and, the value of a human being (motho) is captured in terms of worth insofar as it is inherent, unconditional, and absolute. In other words, ubuntu's talk of recognizing the quality or 
the humanity of others is a call to respect their superlative value (dignity). Human dignity surpasses all other values, and it is in recognition of this individual fact or quality that we should react positively to others by forming sharing relations with them (Toscano 2011). So, at the heart of ubuntu is a creation of a society responsive to the dignity or equality of all human beings. Recognizing others' humanity throws us into particular kinds of relations with them—sharing or caring relations (Ramose 2009, 302).

The value of human beings (qua moral status) is located in their ability to realize their true humanity (capacity for virtue), rather than in their autonomy, as is wont in some dominant Western moral systems. Autonomy respects persons' abilities to lead life as they deem it best for themselves-a situation generally left to individuals to provide moral content, informed by rationality (Berlin 1959). Ubuntu values most about a human being her ability to lead a morally genuine life-a life of virtue:

Man can then be held as a moral agent, a moral subject-not that his virtuous character is a settled matter-but that he is capable of virtue. . . . A person is defined in terms of moral qualities or capacities. (Gyekye 1992, 111)

Gyekye settles the question of what confers moral status to human beings: the capacity for virtue. It is not the actual exercise of virtue that makes one the object of equal moral respect; rather, it this facet of her humanity. A just society recognizes this feature and operates on the logic of care to let individuals develop this ability.

We can conclude that the first condition of a just society is one of equality, captured by the human capacity to develop a virtuous character. All human beings ought to be respected because they possess this onto-moral feature.

\section{The Common Good Condition}

The second consideration constitutive of justice involves the objective goods necessary for human beings to be able to function. It is not enough merely to have the capacity to nurture and develop a virtuous character. For justice to be robust, we need an account of the basic goods necessary for human beings to actualize or realize their moral possibilities. In other words, when we have recognized what it means to be human in terms of the capacity for virtue, it is crucial to supply the sociopolitical and economic goods necessary for moral agents to be able to pursue ubuntu (personhood). This condition in the African moral discourse is usually captured by an appeal to the idea of the common good, an idea that refers to the objective list of all the goods-be they social, political, and economical-necessary for a human life to be possible in the first place (Gyekye 1992, 2004; Wall 2012; Wiredu 1992). The idea of the common good is usually captured by appeal to the Siamese crocodile with two heads and one stomach: 
The part of the motif relevant to moral thought is the single stomach.... The common stomach ... indicates that at least the basic interests of all the members of the community are identical. It can therefore be interpreted to be symbolizing ... the good of all the individuals within a society. (Gyekye 2010)

The idea of the common good is predicated on the idea that humanity is a property identically shared by all human beings. Just like a single stomach, this idea of the common good presupposes a basket of goods and needs that are necessary for a human life to be possible (Gyekye 2004). This idea is transcultural, insofar as it departs from the basic moral belief that there are goods whose fulfillment is a basic requirement for each and every human being; otherwise, life would be handicapped or unfortunate. In another place, Gyekye $(1997,67)$ refers to these goods as human goods. They cover a "list of objective goods" necessary for human perfection (Wall 2012), indeed, for all facets of human life-the political institutions and other necessary social facets for a human life to be possible. It is for this reason that Gyekye notes:

The pursuit of the good of all is the goal of the communitarian society, which the African society is. A sense of the common good-which is a core of shared values - is the underlying presupposition of African social morality. (2010; emphasis mine)

The basic assumption of ubuntu is that human beings manifest diversity and divergence in many areas, but when it comes to what a human being needs to be able to function as a human being and to achieve the moral goal of achieving a sound character, a core of shared values or goods is necessary for all human beings (Gyekye 2004, 2010). Thus, to talk of the common good is to talk of the core goods that all human beings need to self-realize. A just society therefore provides basic goods for a human being to be able to make something of their humanity. ${ }^{6}$

The discussion above suggests that a just society, according to ubuntu, has two crucial facets. First, it functions as the basis of respecting the human capacity for virtue. Human beings are equal in virtue for merely possessing this capacity; it is precisely because human beings have this capacity that morality is possible. Second, justice requires that the basket of human or basic goods is available for human beings to be able to lead a moral life. Conversely, an unjust society is one that does not properly recognize what it means to be a human (moral status) and one that does not provide the common goods necessary for a human being to pursue personhood.

To offer some concreteness to this talk of a just society as imagined by ubuntu, I account for why colonization and apartheid (in South Africa) are great evils, insofar as they are instances of injustice. First, colonization and apartheid were evil precisely because they failed to respect the humanity (capacity for virtue) of African people; hence the racism and sexism that characterized these political regimes. Second, these regimes were evil 
because they systematically removed the common goods necessary for a robust human life. The dispossession of land, the destruction of history, culture, and heritage, the destruction of economies and political structures-all were activities of removing the common good. By taking land and cultural inventions for imagining and navigating life was to make life intolerable for the humanity of African people. The disruption effected by these means made ubuntu/personhood impossible. Apartheid and colonization were evil because, in some sense, they cut off African people from the domain of morality (Molefe 2018a).

To exemplify the robustness of the conditions that constitute a just society, I invoke them to consider the case of Marikana, where at least thirtyeight miners were shot and killed by police after engaging in an illegal strike, demanding salary increases. The case is important because it reveals the ugliness of exploiting cheap black labor-a central facet of colonization and apartheid, to which the postapartheid society has insufficiently responded in imagining a just society (Molefe 2018a). The response offered by the state to the Marikana massacre was to recommend a commission of inquiry, one that never actually sought to redress the vestiges of cheap black labor that remain part of the mining industry in South Africa.

The objector might here argue that talking of respecting persons for their capacity for virtue (dignity) and providing the common good is the same thing as talking about dignity and human rights, as is dominant in Western moral-political discourses. This is far from the truth.

Yes, to talk of respecting persons because they possess a particular capacity is tantamount to talk of dignity, which is a feature of human nature (Toscano 2011), but to talk of the common good is radically different from a talk of rights. The morality of rights imagines entitlements held by individuals against the state and others, which engenders duties owed to them in virtue of these rights (Donnelly 2009; Feinberg 1970). The force of the rights held by individuals is ordinarily understood to trump other social goals or goods (Donnelly 1992; Dworkin 1978). In contrast, talk of the common good imagines a social morality that elevates other-regarding duties as the essence of morality-the idea that we have duties to advance the welfare of (all) others. In this moral scheme, rights are secondary; in fact, they are trumped by the social goals of providing basic needs necessary for each individual to be able to self-realize (Gyekye 2010; Menkiti 1984). This should come as no surprise, given that dignity is a universal feature of most moral systems of the world (Donnelly 1982, 306), but African moral systems tend to respond to the dignity of human beings by emphasizing duties instead of rights:

The substantive issues discussed today in terms of human rights, such as life, speech, religion, work, health, and education, are handled almost entirely in terms of duties that are neither derivative from nor correlative to rights, or at least not human rights. $(1982,306 \text {; emphasis mine })^{7}$ 


\section{Ubuntu and the Ethics of Means}

Development ethics defines development in terms of some moral ends, and it emphasizes that we need just means to secure such ends. The idea of just means, in the discourse of development ethics, is captured in terms of the "means of means" (Dower 2008, 189-90). This facet of development requires the moral evaluation of the options and routes we select to pursue development. For example, Goulet (1996) makes a distinction between the ethical and engineering approaches to development, which signals the crucial difference between ends and means. Development as an ethical enterprise involves some basic or final value, in light of ubuntu, to achieve personhood. Talk of economics, as an engineering approach, refers to economic growth as a means to development.

The methods we employ to pursue development by providing necessary goods, be they food or infrastructure or something else, must be consistent with our moral ideals and goals as specified by the ends we espouse. Put simply, we have many ways to pursue development, but we should employ only those that are morally sound. Take, for example, Dower's talk of means:

One of the things which the ethics of the means brings out is the fact that development ethics has, so to speak, a number of dimensions. Much of development ethics is part of social, political or public ethics; that is, the ethical issues are about how public policies and laws can, for instance, deliver the moral goals of social justice, protect human rights, express democracy, protect the environment, or provide the right education for the next generation. $(2008,189)$

My intention here is to offer a theoretical principle that will account for how the ethics of means is to be understood according to ubuntu. At the heart of ubuntu is the moral goal of achieving a good character, but how does the agent achieve a good character? One salient answer to this question invokes harmonious relationships. The best way to pursue moral perfection is by being embedded in them. At the heart of the ethics of ubuntu is the idea that social relationships serve as the best moral instruments to achieve ubuntu:

At the centre of traditional African morality is human life. Africans have a sacred reverence for life. . . . To protect and nurture their lives, all human beings are inserted within a given community... The promotion of life is therefore the determinant principle of African traditional morality and this promotion is guaranteed only in the community. Living harmoniously within a community is therefore a moral obligation ordained by God for the promotion of life. (Godfrey Onah, quoted in Metz 2007a, 329) 
Here, a different moral end is offered as the goal of African ethics: life. My interest is the means prescribed for securing that end, which is the metaphysical imagination that God naturally inserted human beings within a given community. Morality, we are told, is guaranteed only in the community. Further, relationships deemed morally relevant for securing the good can be characterized in terms of living harmoniously-an obligation required for achieving the moral end of promoting life. In this ethical system [ubuntu], human beings can achieve the ideals of personhood only by living harmoniously with others. The point here is that moral perfection is possible only in cooperative relationships. This same point is appositely captured by Shutte:
The goal of morality according to this moral vision is full- ness of humanity. Moral life is seen as the process of moral growth. Just as participation in community with others is the essential means to personal growth, so participation with others is the motive and fulfilment of the process. $(2009,96$; emphasis mine)

The discussion above makes clear that self-realization is the proper moral end posited by ubuntu as a moral theory; and furthermore, cooperative relationships with others are the essential means for achieving it. The direct implication of this moral logic for the ethics of means is that it will highly prize paths and options that are participatory and cooperative. Development, if it is one influenced by ubuntu, must involve people's participation and cooperation, directly or by representation.

This way of thinking about means will have implications for how decisions will be made about which paths or options are to be followed in pursuing development: consensus will be the characteristic feature of making decisions about policies (Gyekye 1992; Wiredu 1996). In other words, policy options that will be the most consistent with ubuntu are those that emerge in the context of deliberations that result in consensus, rather than majoritarianism or external impositions. This is so because majoritarianism marginalizes the minority, but consensus seeks a decision as accommodative as possible, with no losers and no winner-take-all attitude (Wiredu 1996).

Another crucial facet to consider is to approach development in ways that are consistent with the cultural values of ubuntu. Here, by values, I am specifically referring to norms that are salient and characteristic of a particular place and culture: customs (Wiredu 1992, 193, 2008, 334-36). For example, some of the cultural values salient among African people are the value of consensus over majoritarianism; the fundamental goal of reconciliation and not retribution; to imagine socially cooperative ways to build wealth or economies as opposed to individualist and competitive ones; to distribute goods on the moral logic of needs and care, as opposed to that of rights (Metz 2007a, 324-26). These cultural values are consistent with a society that highly values the possibilities of each individual to realize her 
own true self. These values emphasize the duty to respond positively to individuals who may be in need for the sake of ensuring they are not obstructed from their goal of personal development.

In light of the above, we see that a just society is one that truly respects human beings for their capacity for virtue and one that puts in place conditions necessary for human beings to self-realize. These conditions operate on the logic of love and responsibility, not rights (Molefe 2018b). Each individual and social institution has a mandate to respond caringly to individuals' needs and provide social goods for individuals to be able to pursue personal perfection.

\section{Conclusion}

Ubuntu, construed within the theoretical prism of development ethics, imagines a robust society as one that creates and provides material, social, and political resources for individuals to be able to pursue moral perfection. The ethics of means imagined by ubuntu is one that accentuates cooperation and participation as the best way to pursue development, which takes seriously our capacity for moral perfection as the crucial moral focus and is participatory and rooted in (African) cultural modes of being in the world.

Several consequences flow from this conception of development. This approach repudiates the tendency in many parts of Africa to reduce development to modernization, that is, the inclusion of markets and labor markets (employment), the introduction of malls and shopping complexes, and so on. Development is about individuals and people, specifically, their ability to be the best they can be, morally speaking. Another crucial consequence related to this conception of development has to do with the way we understand politics, which, in this view, is about the state that functions to create an overall social life that enables individuals, groups, cultures, and institutions to enable individuals to flourish. This conception of a state will not be one that is neutral or indifferent regarding a good life, as is common in the liberal political approaches-the so-called imperfect state. The state has a duty to create conditions and support the things that enable ubuntu.

The last consideration involves recognizing two influential approaches to the discourse of development, namely, the human rights and capabilities approaches. I have expressed my suspicions about the relevance of rights in this discourse (see also, Molefe 2019, ch. 6). For future research, it will be important to compare these approaches. The capabilities approach unfolds ten central human functional capabilities that constitute a dignified life, such as life, bodily integrity, affiliation, and so on. It will be interesting for future researchers to compare ubuntu to this approach, to see whether it will offer a different list, and to explore the rationale it will give for this list, or any other list of what constitutes a decent life. 
1. Though the discourse on development may be criticized for being a Western imposition, or to have serious moral, ideological, and political objections, I pursue the discourse on development through the prism of development ethics because it seeks to overcome the objectionable facets of this discourse and practice of development. Second, I engage in this discourse using the framework of development ethics because it urges perspectives from various cultural contexts to contribute to the discourse of development. Hence, in this context, I draw from the indigenous moral concept of ubuntu to construe an African conception of development.

2. I limit myself to these two questions for one major reason: many writers concern themselves with environmental ethics by drawing from ubuntu, but they do not generally grapple with the question of a just society (Behrens 2011; Chemhuru 2016; Metz 2012; Tangwa 2004). Therefore, it will be interesting and a significant contribution to the literature to focus on the underexplored question of what is to count as a just society. Many scholars of ubuntu have reflected on what a good life might be, but few African philosophers theoretically reflect on the question of a just society (Shutte 2001).

3. Two other recent and useful approaches to the discourse of ubuntu exist: Praeg (2014) defends a conception of ubuntu that he construes in terms of critical humanism; Etieyibo (2017) articulates a strict cosmopolitan view of ubuntu. I do not consider these accounts in this article for two reasons. First, I do not have space to consider all accounts of ubuntu in this analysis; it is more useful, I stipulate, to engage a discourse of ubuntu that is more salient and well discussed in the literature (that of Metz), than ones that are underexplored in the literature, like that of critical humanism and strict cosmopolitanism. This does not imply that these interpretations of ubuntu are implausible or less important; they will require careful consideration in a different context. Second, I find the critical humanism and strict cosmopolitan interpretations of ubuntu to be seriously objectionable for reasons that are beyond the scope of this article. It suffices for now merely to express my concerns in this fashion. I do not find the inclusion of the concept of the critical (in critical humanism) in discussing the humanism characteristic of ubuntu to introduce problematic meta-ethical implications that ubuntu is best construed in terms of moral constructivism. I find the strict cosmopolitan view of ubuntu to fly against the meta-ethical commitment to partiality that is characteristic of it as a moral theory.

4. I caution the reader that not all scholars of African ethics who espouse the normative idea of personhood imagine it within the rubric of ubuntu. It is the assumption—or stipulation—of this article that these two moral concepts have more or less the same moral content.

5. A reviewer presses me to justify why I consider ubuntu to be best construed in terms of virtue and not deontology or consequentialism, for example. I am grateful to the reviewer for pressing me on this issue. Several reasons lean on the interpretation of virtue. First, the words used to discuss morality in most African cultures tend to emphasize virtues of character: Gyekye (2010) offers a useful sample of African languages and their emphasis on character as the focus of morality. Second, the language employed by scholars of ubuntu and scholars who speak specifically of personhood (I presume that it is not offhanded to assume that they amount to the same moral system) largely tend to use the language of character, moral excellence, or virtue to capture these terms. 
6. A reviewer presses me at least to acknowledge that Emmanuel Eze registered a criticism against the idea of the common good (see https://them.polylog.org/2/fee-en.htm). Eze disputes the claim that ultimately the interests of all members of a society are the same. I do not have space to solve this substantive issue here. Two comments, however, will suffice for now. There is consensus in the literature that Afro-communitarian moral-political thought is committed to the idea of the common good (Bujo 2001; Eze 2005; Gyekye 2010). I am merely drawing from this axiomatic assumption to give an account of a just society. Second, the idea of the common good is axiomatic in the communitarian discourse, just as the idea of rights is the dominant conception of a just society in the liberal political tradition. One can always dispute the idea of rights, and one can always point out that it is a controversial view; but that is not to take away the fact that it is a central article of faith of liberal political conceptions of justice. The same is the case regarding the idea of the common good in communitarian politics: it is an article of faith in this political approach. I do not have space to justify why this idea is taken seriously in Afro-communitarian thought.

7. The reader might find this discussion to be rough and brief; in fact, a reviewer has requested that I justify why rights cannot be employed to secure human dignity. Space will not allow me to devote an extensive discussion on this point, but I am glad to point the reader to my published works that deal with the relationships between ubuntu/personhood and the idea of rights in African philosophy (Molefe 2017a, 2017b, 2018b).

\section{REFERENCES CITED}

Behrens, Kevin. 2011. African Philosophy, Thought and Practice and Their Contribution to Environmental Ethics. Johannesburg: University of Johannesburg. . 2013. “Two 'Normative' Conceptions of Personhood." Quest 25: 103-19.

Berlin, Isaiah. 1959. Four Essays on Liberty. Oxford: Oxford University Press.

Biko, Steve. 2004. "Some African Cultural Concepts."In I Write What I Like, 40-47. Johannesburg: Picador Africa.

Bujo, Benezet. (1998). The Ethical Dimension of Community: The African Model and the Dialogue between North and South. Translated by C. Namulondo. Nairobi: Pauline's Publications Africa.

-2001. Foundations of an African Ethic: Beyond the Universal Claims of Western Morality. New York: The Crossroad Publishing Company.

Chemhuru, Munamato. 2016. The Import of African Ontology for Environmental Ethics. Johannesburg: University of Johannesburg.

Collier, David, Fernando Daniel Hidalgo, and Andra Olivia Maciuceanu. 2006. "Essentially Contested Concepts: Debates and Applications." Journal of Political Ideologies 11: 211-46.

Crocker, David. 1991. "Towards Development Ethics." World Development 19: 457-83.

Darwall, Stephen. 1977. “Two Kinds of Respect." Ethics 88: 36-49.

DeGrazia, David. 2008. "Moral Status as a Matter of Degree?" Southern Journal of Philosophy 46: 181-98.

Donnelly, Jack. 2009. Human Dignity and Human Rights. Denver: Josef Korbel School of International Studies.

Dower, Nigel. 2008. "The Nature and Scope of Development Ethics." Journal of Global Ethics 4: 183-93.

Dworkin, Ronald. 1978. Taking Rights Seriously. Cambridge, MA: Harvard University Press. 
Etieyibo, Edwin. 2017.“Ubuntu, Cosmopolitanism and Distribution of Natural Resources." Philosophical Papers 46: 139-62.

Eze, Onyebuchi. 2005. “Ubuntu: A Communitarian Response to Liberal Individualism.” Master's thesis, University of Pretoria.

Feinberg, Joel. 1970. "The Nature and Value of Rights." The Journal of Value Inquiry 4: 243-57.

Fine, Ben. 2009. “Development as Zombieconomics in the Age of Neoliberalism." Third World Quarterly 30: 885-904.

Goulet, David. 1995. Development Ethics: A Guide to Theory and Practice. New York: The Apex Press.

—. 1996. "Development Ethics: A New Discipline." International Journal of Social Economics 24: 1160-71.

Gyekye, Kwame. 1992. Person and Community. Ghanaian Philosophical Studies, 1. Washington, DC: Council for Research in Values and Philosophy.

2004. Beyond Cultures: Perceiving a Common Humanity, Ghanaian Philosophical Studies. Accra: Ghana Academy of Arts and Sciences.

_ 2010. "African Ethics." The Stanford Encyclopedia of Philosophy, edited by Edward N. Zalta. http:// plato.stanford.edu/archives/fall2011/entries/african-ethics.

Ikuenobe, Polycarp. 2006. Philosophical Perspectives on Communalism and Morality in African Traditions. Lanham, MD: Lexington Books.

Kant, Emmanuel. 1996. Groundwork of the Metaphysics of Morals. Translated by Mary Gregor. Cambridge: Cambridge University Press.

Larmore, Charles. 2012. "What Is Political Philosophy?" Journal of Moral Philosophy 10: 276-306.

Lutz, David. 2009. "African Ubuntu Philosophy and Global Management." Journal of Business Ethics 84, 313-28.

Mbigi, Lovemore. 2005. The Spirit of African Leadership. Randburg: Knowers.

Menkiti, Ifeanyi. 1984. "Person and Community in African Traditional Thought." In African Philosophy: An Introduction, edited by Richard Wright. Lanham, MD: University Press of America.

Metz, Thaddeus. 2007a. "Toward an African Moral Theory." The Journal of Political Philosophy 15: 321-41. 2007b. "Ubuntu as a Moral Theory: Reply to Four Critics." South African Journal of Philosophy 24: 369-87.

- 2011. "Ubuntu as a Moral Theory and Human Rights in South Africa." African Human Rights Law Journal 11 (2): 532-59.

- 2012. "An African Theory of Moral Status: A Relational Alternative to Individualism and Holism." Ethical Theory and Moral Practice: An International Forum 14: 387-402.

Mokgoro, Yvonne. 1998. "Ubuntu and the Law in South Africa." Potchefstroom Electronic Law Journal 1: 1-11.

Molefe, Motsamai. 2017a. "Critical Comments on Afro-Communitarianism: The Community versus Individual." Filosofia Theoretica 6: 1-22.

. 2017b. "Relational Ethics and Partiality: A Critique of Thad Metz's 'Towards an African Moral Theory."' Theoria 64: 53-76.

2018a. "Personhood and (Rectification) Justice in African Thought." Politikon 45: 352-67.

2018b. "Personhood and Rights in an African Tradition." Politikon 45: 217-31.

- 2019. An African Philosophy of Personhood, Morality and Politics. New York: Palgrave Macmillan.

Molefe, Motsamai, and Nolubabalo Magam. 2019."What Can Ubuntu Do? A Reflection on African Moral Theory in Light of Post-Colonial Challenges." Politikon 46: 311-25

Munyaka, Mluleki, and Mokgethi Mothlabi. 2009. "Ubuntu and Its Socio-Moral Significance." In African Ethics: An Anthology of Comparative and Applied Ethics, edited by Munyaradzi Felix Murove, 324-31. Pietermaritzburg: University of Kwazulu-Natal Press. 
Nkondo, Muxe. 2007. "Ubuntu as a Public Policy in South Africa: A Conceptual Framework."International Journal of African Renaissance Studies 2: 88-100.

Praeg, Leonhard. 2014. A Report on Ubuntu. Pietermaritzburg: University of KwaZulu of Press.

Ramose, Mogobe. 1999. African Philosophy through Ubuntu. Harare: Mond Books.

- 2009. "Towards Emancipative Politics in Africa." In African Ethics: An Anthology of Comparative and Applied Ethics, edited by Felix Murove, 308-14. Pietermaritzburg: University of Kwa-Zulu Natal Press.

Sebidi. John. 2008. Towards the Definition of Ubuntu as African Humanism. Paper. Private Collection.

Sen, Amartya. 1987. On Ethics and Economics. Oxford: Basil Blackwell.

Shutte, Augustine. 2001. Ubuntu:An Ethic for a New South Africa. Pietermaritzburg: Cluster Publications. 2009. “Ubuntu as the African Ethical Vision.” In African Ethics: An Anthology of Comparative and Applied Ethics, edited by Felix Murove, 85-99. Pietermaritzburg: University of Kwa-Zulu Natal Press.

Tangwa, Godfrey. 2004. "Some African Reflections on Biomedical and Environmental Ethics." In Companion to African Philosophy, edited by Kwasi Wiredu, 287-95. Oxford: Blackwell Publishing.

Toscano, Mauel. 2011. “Human Dignity as High Moral Status”. The Ethics Forum 6: 4-25.

Tutu, Desmond. 1999. No Future without Forgiveness. New York: Random House.

Van Niekerk, Jason. 2007. "In Defence of an Autocentric Account of Ubuntu." South African Journal of Philosophy 26: 364-68.

Wall. Stephen. 2012. "Perfectionism in Moral and Political Philosophy." The Stanford Encyclopedia of Philosophy, edited by Edward N. Zalta. http://plato.stanford.edu/archives/win2012/entries /perfectionism-moral/.

Wiredu, Kwasi. 1992. "Moral Foundations of an African Culture." In Person and Community. Ghanaian Philosophical Studies 1, edited by Kwasi Wiredu and Kwame Gyekye. Washington, DC: Council for Research in Values and Philosophy.

—. 1996. Cultural Universals and Particulars: An African Perspective. Indianapolis: Indiana University Press.

2008. “Social Philosophy in Postcolonial Africa: Some Preliminaries Concerning Communalism and Communitarianism." South African Journal of Philosophy 27: 332-39.

_ 2009. "An Oral Philosophy of Personhood: Comments on Philosophy and Orality." Research in African Literatures 40: 8-18.

MOTSAMAI MOLEFE is a Senior Researcher at the University of Fort Hare. His research focuses on African philosophy, Moral and Political Philosophy, and particularly on ubuntu, personhood, dignity, development, historical injustices, and human rights. He is currently working on a book on African bioethics. 